International Journal of Scholarly Papers for Media and Communications

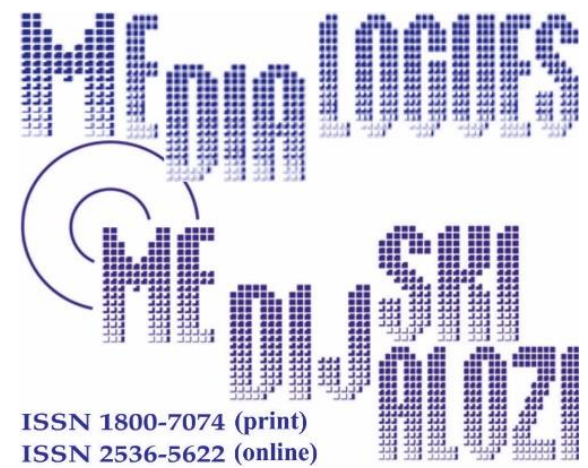

Bojovic, B. (2018), „Linguistic and Cultural Analysis of Advertising: How Ideologies and Language Shape Consumer Perception", Media dialogues / Medijski dijalozi,

Vol. 14, No. 3, pp. 7-22.

\title{
Linguistic and Cultural Analysis of Advertising: How Ideologies and Language Shape Consumer Perception
}

\author{
Associate Professor BRANKICA BOJOVIC, \\ University of Montenegro \\ Podgorica, Montenegro
}

\begin{tabular}{|c|c|}
\hline $\boldsymbol{A} \boldsymbol{R} \boldsymbol{T} \boldsymbol{I} \boldsymbol{C L E}$ & $\begin{array}{c}\text { Received: February 27, 2021 / Revised from: March 27, 2021 } \\
\text { I N F O }\end{array}$ \\
\hline DOI & Accepted: April 27 2021 / Available online: July 15, 2021 \\
\hline
\end{tabular}

\section{ABSTRACT}

The discourse of advertising is intrinsically multidisciplinary, as it involves linguistic, social, psychological, economic, political and cultural factors that have all played a significant role in the history of advertising. As the process of globalisation gains momentum, so does the expansion of businesses and economies and the migration of populations. Yet, the uniqueness of individual cultures prevails and demonstrates that the process of communication and translation are matters of not only 
linguistic, but also cultural transferral. Therefore, even the world of business and advertising - a world of fast food, fast production and fast living - is programmed in accordance with the uniqueness of those cultures. This paper will address, through illustrative examples, the fact that culture, beliefs, ideologies, values and societal expectations permeate the sphere of advertising. This paper aims to showcase that the combination of linguistic and culturological analysis of the discourse of advertising gives a conceptually broader analysis than individually. It employs a method of comparative overview of previous academic research in linguistic analysis of advertising and of cultural and social studies that have contributed to a demystification of the discourse of advertising.

KEYWORDS: Culture, Ideology, Linguistic Analysis in Advertising, Linguistic and Visual Metaphors, Propaganda

\section{INTRODUCTION}

The discourse of advertising messages is primarily characterised by persuasiveness, which is achieved through linguistic and visual means, and most frequently by a combination of both. The linguistic content of advertise- ments cannot be analysed in isolation, but as part of a complex system that is formed of language, context, visual and audio means (Cook, 2001, pp. 3-9). The area of marketing and advertising is particularly suitable for linguistic research as a result of the global proliferation of advertisement messages. With globalisation and the ever-intensifying expansion of advertising, which has spread from newspapers and television onto the internet and social media, further intensified by big data management, there seems to be no escape from the impact of advertising.

Despite the fact that technological innovations render the advertising process rather straightforward, advertisements must still have substance, and must be creative in order to appeal to the target audience. For this particular reason, language and visual material play a major role in advertising, and a great deal of financial resources are dedicated solely to marketing departme- nts in a range of industries (O'Connell, 2014). Pop-up advertisements that emerged as a phenomenon in the 1990s are still in existence at present. However, internet users can, and quite frequently do, eliminate pop-ups from their browsers with various ad-blocking extensions. The trend of ad-blocking is on the increase as a result of ad-proliferation, but visual material is still invariably present on the radio and TV, in print media, on billboards, in leaflets, as well as on social media platforms.

The persuasive discourse of advertising is non-reciprocal, i.e. communication only flows in one direction, which means that the recipient of the message cannot possibly give communicative feedback as he/she would in a conversational discourse (Lakoff, 1981, pp. 25-42). This is why persuasiveness implies passivity: the recipient is exposed to stimuli, without having control over the source of those stimuli. 
However, the recipients are also expected to have a reaction to advertisements, preferably a positive one. Ideally speaking, the relationship between the sender and the recipient would end at that particular point where one side makes a profit, and the other, i.e. the recipient, receives goods that match their needs or tastes.

However, research that looks into the cultural aspects of advertising clearly demonstrates that the relationship between the sender and the recipient is not one of a pure exchange of goods; instead of selling a product, the sender is selling an ideology or an idea which the product embodies. In addition to providing an overview of empirical research in this area, this paper will look into the history and evolution of advertising, propaganda and public relations. Advertising implies utilising persuasive techniques of communication, via mass media, with the aim of reaching a large target audience, informing them about products or services and presenting the product in accordance with the desires of the buyers (Morierty, Mitchel, and Wells, 2012). Therefore, the product itself is subject to manipulation and the final objective is to manipulate the clients' perception of the product so as to induce appeal, desirability and identification with the brand.

In an attempt to provide insight into the linguistic aspects of the analysis of advertisement messages, this paper will also address the formation of slogans and brands, with particular focus on metaphors and the combination of linguistic and visual content in advertising.

\section{CULTURAL ASPECT OF ADVERTISING}

Plenty of research has been conducted with the aim of comprehending the full spectrum of the impact of advertising messages. A historical overview of the development of advertising as a discipline points to the early 1900s as the origin of the manipulation of public opinion, i.e. propaganda. Edward L. Bernays, the "father of propaganda", and his work have been the subject of criticism from multiple aspects.

Noam Chomky, one of the most zealous opponents to propaganda and media manipulation, has written volumes on the subject matter (e.g. Manufacturing Consent: The Political Economy of the Mass Media, 1988; Propaganda and the Public Mind, 2001; and On Power and Ideology, 1987), including the institutions and means of manipulation of the minds of the public. The gist of Chomsky's argument in Manufacturing Consent is that the ultimate objective of propaganda is to "inculcate individuals with the values, beliefs, and codes of behaviour that will integrate them into the institutional structures of the larger society ... In countries where the levers of power are in the hands of a state bureaucracy, the monopolis- tic control over the media, often supplemented by official censorship, makes it clear that the media serve the ends of a dominant elite" (Herman et al., 1988, pp. 5-16). 
Yet, Bernays (1928, pp. 958-971) presents the act of manipulating the public opinion as one of the privileges of democracy, an act that was once exclusive to kings and tribal leaders, and an act that rightfully stood at every-one's disposal at the onset of the 20th century. It was his firm belief that mass manipulation was absolutely necessary, and primarily employed by new leaders and the advocates of new ideas, in a social struggle against inertia. Thus, what is at present criticised as mass manipulation of the population was once advocated as a social necessity in the process of annihilating the weight of traditional beliefs, stereotypes, oppressive and tyrannical ideologies, but also as an industrial necessity, which is where advertising comes into play. It is remarkable that Bernays does address the issue of potential abuse of propaganda tools to instil fascist, racist or generally discriminatory ideals, yet claims that propaganda simultaneously educates the public on the severity of its impact (Ibid.). This stance stands in direct opposition to Chomsky's, formulated six decades after Bernays' views on the need to manipulate public opinion was published.

Among the first subjects of Bernays' advertising work was the tobacco industry in the USA at the end of the 1920s. In the meantime, his work had become so popular among the industrialists that he formed the first council for public relations, and the manipulation of public opinion became the most dominant factor in the relationship between industries and consumers (Brandt, 2007, pp. 26-49). His most prominent campaign was launched for Lucky Strike, and it nearly coincided with the suffrage movement in the USA, and the adoption of the 19th Amendment in 1920. The essential objective of the Lucky Strike campaign was to capitalise on the momentum that the suffrage movement had gained and promote smoking as an act that women freedom- fighters could identify with, since smoking had been a symbol of men's social superiority over women.

In the Lucky Strike Reach for a Lucky campaign, Bernays worked under Lucky Strike's management, which had ambitions of doubling their market, and, while trying to produce an ideal campaign for targeting female users, participated in the creation of the ideal appearance of the female form (Ibid.). The campaign revolved around promoting cigarettes as a method of losing weight, certified and intensively promoted by doctors and scientists in the print media. Thus, Bernays managed to tap into the values of a culture, and partake in the moulding of a new female identity that would remain dominant for decades. His initial theory became a self-fulfilling prophecy - "As for the companies interested in gaining acceptance for new inventions, how can they over-come the inertia of the public without applying some stimulus to the public opinion?" (Bernays, 1928, pp. 958-971).

Advertising went beyond the role of merely promoting a product; it turned products into symbols with which consumers could identify at an ideological level. The values of a society - the culture of a society-are, in part, represented by ideologies, along with the beliefs, norms, traditions and preferred modes of behaviour (Lewis, 2005, pp. 9-15). The impact of propaganda in advertising is evident from the previously provided example, especially if we bear in mind the fact that smoking had been 
considered taboo among women prior to the intensive campaign led by Bernays. It triggered a new current in advertising that has managed to prevail to this day.

Evidently, the implications of advertising or of the stimulus to public opinion have played an important role in the evolution of cultural identities worldwide. Since the implications are not necessarily positive, as Bernays claimed, the use of the means of propaganda in advertising - the instilment of ideologies, beliefs and values - has undergone harsh criticism and such views are by no means a novel phenomenon. Durand and Lambert reflect upon an array of studies that addressed allegations regarding the distastefulness and offensiveness of advertising, and the assumptions that it manipulates people into thoughtless consumerism (Durand, and Lam-bert, 1985, pp. 9-17).

Empirical studies on the cultural and ideological implications of advertising contain analyses of the political, social and economic factors of the second half of the 20th century. Some of those studies have brought to light the layers of sexism, chauvinism, racism, discrimination and stereotyping that underlined advertising in the 1950s, 1960s and 1970s. Over time, these matters have become a regular discussion topic, and much has been done in the previous decade by governments (in the EU, and globally), as well as on social media (e.g. Facebook) to prevent further expansion of discriminatory advertising.

Criticism of advertising has prevailed until the present day. One of the major topics is the abuse of women's sexuality, i.e. the creation of a narrative of everpresent and ever-desired sexuality - a phenomenon known as the hy- persexualised Eve. The hypersexualised Eve is a feminist narratological analysis of how modern advertising recounts the tale of Genesis, with the focus on Eve, the archetypal woman, and the ideal symbol of femininity. Bernay's ideas on propaganda are an integral part of the narrative that modern advertisements "featuring Eve are selling not only products, but also conceptions of womanhood and femininity" (Colette, 2015, pp. 5-24).

This effect can be explained by the fact that the subtext of advertisements involves objects of appeal and sexuality, which explains the anticipation of pleasure among consumers - the pleasure that the act of purchasing a product brings. Within that context, sexuality represents the foundation of modern consumerism (Berger, 2015, pp. 99-118).

The conceptions of womanhood and femininity pitch a product to the reader by eroticising the woman who is the focal point of the advertisement. Devoid of the original context of Genesis, the archetypal woman is reduced to sexuality. Therefore, women, as the target audience, are asked to embrace that sensual form of sexuality by purchasing the product (whether it is perfume, make-up, a watch, clothes, etc.). The reduction of women's identity and femi- ninity to sexuality is the focal point of criticism of advertising, particularly within the feminist discourse. It is perceived as 
repressive (regardless of the original intentions of the advertiser), as it imposes unrealistic expectations on both sexes regarding the ideal female form.

Advertising imposing ideal body images on both men and women has also been a widely discussed topic in the academia, public debates, and the social media. Zotos and Tsichla (2014, pp. 446-454) provide an overview of the academic research at a global level conducted since the 1970s up to the present day, dedicated to studying the role of women in advertising, which ranges from the housewife, a sex object, the subordinate of men or a decorative object. These themes have acted as solid anchors in advertising and still dominate the advertising discourse today. The ideal body image is most frequently presented through the role of the woman as a sex (rather than the previously discussed sexualised) object.

A similar piece of research encompasses only advertisements on the territory of the USA, and covers a period of five decades, 1950-2010. The study concludes that advertisements that promote the role of the woman as a housewife and as someone incapable of making important decisions are decreasing. However, it also reaches the conclusion that the role of the woman as a sex object has been increasingly present in advertisements, which has a detrimental impact on both sexes, and is further fuelled by consumerism (Mager and Helgeson, 2011, pp. 238-252).

It is interesting to note that the rise of feminism, as symbolised by the suffrage movement, was the ideology that Bernays leveraged for his campaigns with the tobacco industry, and yet feminist ideals are seen as a victim of 20th-century advertising campaigns. Naturally, there are notable exceptions to this, otherwise, standard practice, such as the series of campaigns that Dove launched with plus-size models, in an attempt to promote the natural looks of real women (Real Beauty, Love Your Curls, Evolution and other campaigns). The advertisements include women of different colours, nations, shapes and sizes, which initially yielded a positive reaction among the public.

However, there is a body of criticism addressing the negative aspects of the pronatural-beauty Dove campaign (Beale, Malson and Tischner, 2016, pp. 378-386). Once again, the view of the woman was perceived as restrictive, reverting back to imposing the role of the traditional, "domestic" wife, and to presenting another artificial model of what a natural look is supposed to be. The campaigns were also perceived as attempts at boosting feminist consumerism (Johnston and Taylor, 2008, pp. 941-966).

Despite the fact that internet users can easily eliminate distracting advertisements in either visual or audio form, advertising continues to dominate the lives of the general public through mass media and mass consumption. As Bernays explained, in the age of mass production, mass distribution of ideas is required (Bernays, 1928, pp. 958-971). The future of advertising and its impact on individual and group ideologies remains to be seen. 


\section{LINGUISTIC ASPECTS OF ADVERTISING - BRANDS AND SLOGANS}

Phonetic symbolism is a major point of interest in advertising (Boltz et al., 2016, pp. 1088-1092). The topic of symbolism of particu- lar sounds, and how they affect the recipients of the message is particularly significant. Therefore, this was mostly addressed in the context of brand nam- ing, where the phenomenon of sound symbolism plays a critical role. Prozak, Amazon, Aspirin, Chanel, Nivea, AxE, Toyota, etc. are all examples of phonetic symbolism put to use in brand naming. Lexicon is one of the leading companies in this field and the creator of brand names such as Pentium, BlackBerry, Swiffer, Verizon and many others.

Illustrations of how effective sound symbolism is, although it transcends the level of a human's conscious interpretation, can be found in both linguistic and psychological research. Wolfgang Köhler, in his work Gestalt Psychology illustrates sound symbolism through the so-called Köhler's puzzle. The participants in his study were asked to associate words with meaningless shapes, and the study established that fricatives and affricates were linked with sharp objects, and vowels, glides and nasals were linked with rounded ones (Köhler, 1947).

Sound symbolism is certainly not a modern phenomenon. Edward Sa- pir wrote A Study in Phonetic Symbolism in 1929, and Paul Debouille wrote Poésie et Sonorité in 1961, where he tried to prove empirically the suggestive power of phonemes in poetry. A subset of phonetic studies, called acoustic phonetics, studies and classifies sounds according to their acoustic signal, i.e. frequency, amplitude and harmony.

The phonetic effects of brand names on consumer judgments have been subject to empirical studies. The ultimate aim of this empirical research has been the evaluation of the impact of brand names on consumers. Yorkston and Menon provide an overview of previous research, and conduct their own study, illustrating that sound symbolism affects brand perception, and brand evaluation (Yorkston, and Menon, 2004, pp. 43-51). Additionally, there is evidence that phonetic symbolism also influences how memorable brand names are (Boltz et al., 2016, pp. 1088-1092).

Unlike brand names, slogans are not as frequently studied from the perspective of sound symbolism, but rather from a pragmatic viewpoint. Slogans do rely on rhetorical devices and word plays, but they also serve the purpose of sending a message to the general public - there is a sender and a recipient of the message - and can be viewed through the prism of Speech Act Theory (Kissine, 2008, pp. 1189-1202). Three different types of speech acts may be isolated:

The locutionary act is the grammatically correct, meaningful act of speech; An illocutionary act is the pragmatic force of the speech act, i.e. the speaker's intention to apologise, pose a question, command, promise, guarantee, convince, etc. through the act itself. 
A perlocutionary act is the act's effect - whether the recipient is persuaded, scared, enlightened, inspired, surprised, convinced, etc., which means that the recipient's state, knowledge, experience and stance are being affected by the sender (Solomon et al., 2006, pp. 74-78).

Slogans such as Nike's Just Do It, Sainsbury's Try Something New Today; Sony's Be Moved, Wallmart'sSave Money, Live Better, HSBC's The World's Local Bank and DHL's Excellence. Simply Delivered - are all examples of commands (to just do it, to try something new, to be moved, to save money), promises (of simple delivery of excellence) and guarantees of quality and success. Thus, the sender of the message, i.e. the advertiser, is performing the illocutionary act by recommending, suggesting, advising or guaranteeing the quality of a certain product or service.

Graphology is a minor point that needs to be addressed within the context of brand names and slogans, although it falls within the scope of the visual, rather than linguistic, aspect of advertising. Advertising uses paralanguage to a large extent, even in written form, and particularly through iconic use of letters, i.e. the shape, size, colour and the overall design, but also through the use of general signs and, at present, emoticons (Cook, 2001, pp. 3-9). Advertisements frequently resort to the usage of graphology with the aim of evoking an emotion or a mood in the recipient of the message. Graphology also leaves room for creativity in the context of graphical intertextuality, cases in which advertisements contain a particular typeface or font.

Memorable, smart, witty and convincing slogans and sonorous brand names are important in the process of retention of the brand and the product/service. Engaging slogans have an effect that resembles that of deciphering a metaphor - the recipient of the message must invest time and effort in order to understand the hidden meaning, and is consequently more likely to form a positive association with the advertisement (Berger, 2015, pp. 99-118). Similar- ly, the more effort that is required to interpret a slogan, the more likely it is that the recipient of the message will store it in his/her long-term memory (Solomon et al., 2006, pp. 74-78).

The knowledge structures in which information gets stored are referred to as spider webs because the nodes (pieces of information) are connected with other nodes via associative networks. In this manner, consumers form positive associative links between the concepts that the advertisements promote (such as the concept of femininity and womanhood placed in the previously mentioned examples of the hypersexualised Eve), and the product that the advertisement sells. For this particular reason, celebrities are frequently featured in advertisements, as consumers are prone to associating the product with the fullness of the appeal of the featured celebrity, as illustrated in Figure 1. 


\section{METAPHORS AND TRANSLATION IN ADVERTISING}

Metaphor and metonymy are among the most powerful tools used by advertisers in the process of eliciting an emotional response among consumers (Berger, 2015, pp. 99-118). The reason behind the frequent use of rhetorical devices in advertising is the fact that the recipient of the message invests more time and mental energy into understanding and interpreting a rhetorically coded message, derives pleasure from the process, and thus remembers and appreciates the advertisement (Van Hooft et al., 2013, pp. 351-364).

Forceville (1996, pp. 19-21) was among the first researchers to provide an overview of studies on the presence of visual and linguistic metaphors in advertising in the 1980s and early 1990s. The most frequent form of visual metaphor literally enacts the linguistic metaphor. Cook provides the example of an insurance company's advertisement in which their competitor literally steals the shirt from one's [i.e. their customers'] back) (Cook, 2001, pp. 3- 9).

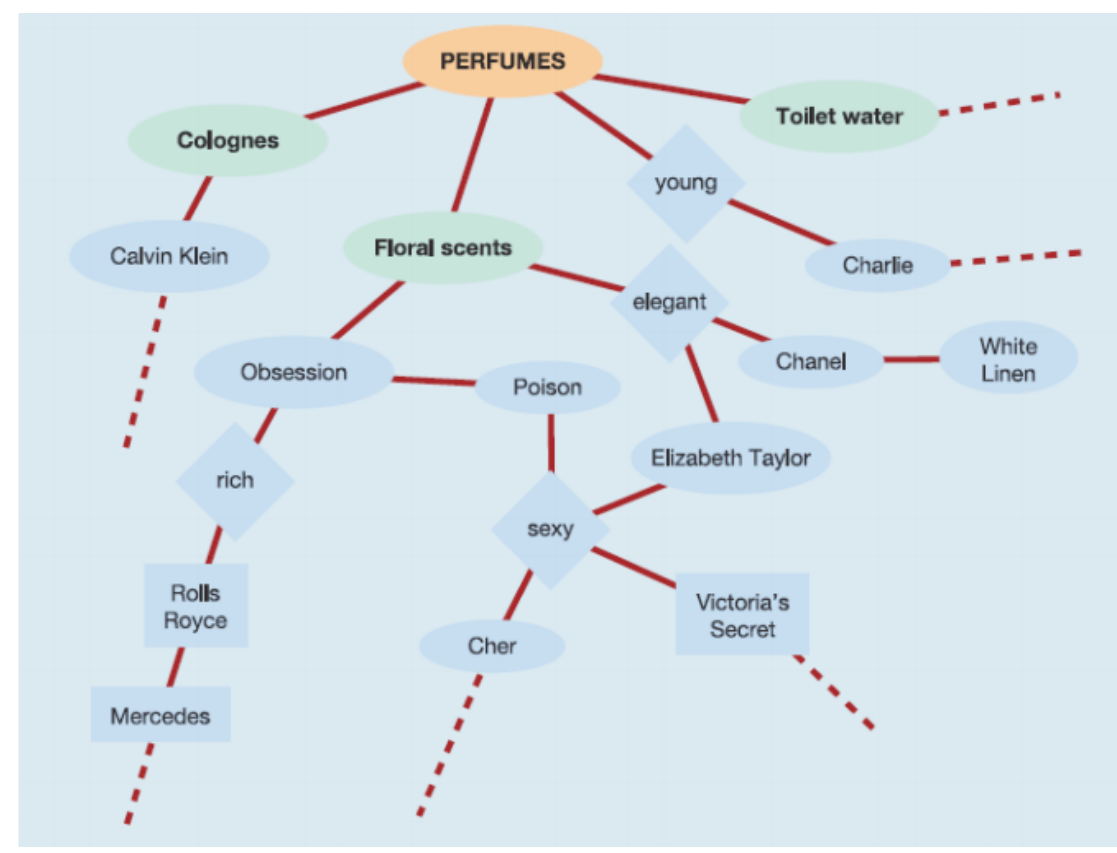

Figure 1. An example of the associative network for perfumes

Source: Köhler, 1947.

Lakoff and Johnson's Cognitive Metaphor Theory (CMT) proposes that the majority of our concepts are abstract, and that they "are defined metaphor-ically in 
terms of concepts that are more concrete and more clearly structured on their own terms", such as "he has a wealth of ideas", where the concept of an idea is defined by the concept of money (Lakoff and Johnson, 1982, pp. 195-208). As each concept contains a domain, metaphors are, in actuality, cross-domain mappings in the conceptual system (Lakoff and Johnson, 1980). Since metaphors are cognitive concepts, and not just linguistic devices, they are re- markably influential tools for persuasion (Zantides, 2016, pp. 65-74).

CMT has been used in numerous studies on visual metaphors in public advertisements because it serves as a solid theoretical foundation for the interpretation of the effect of advertisements on consumers. Alosque scrutinises visual wine metaphors in advertisements and introduces the CMT as the theoretical framework that explicates how cross-domain mapping enables the interpretation of visual metaphors (Alosque, 2015, pp. 125-131). "In the cognitive view, visual metaphor is the pictorial representation of a metaphorical concept" (Ibid., pp. 309-315).

The examples used in this study clearly illustrate that visual metaphors present a certain product as being tasty, of high quality and elegant through a conceptual similarity between the product itself (the domain of wines) and the positive domains of beauty, art or lavishness. For example, the domain of wi- nes, visually represented by a glass of wine, is conceptually linked with the domain of lavishness, visually represented by a man in a dinner jacket holding the glass. In a similar study, the same author proposes that similarity between two domains is not necessarily conceptual; it may also have a perceptual basis (e.g. the golden colour of beer may be perceptually associated with a golden anvil) - Ibid., pp. 234-240.

Visual advertisements are frequently used in combination with text, which acts as a support for the visual metaphor, or completely reveals the meaning of the image (Ibid.). Telibaşa and Zantides reach the same conclusion in their studies on food advertisements and on visual metaphors - that of the metaphor facilitating the transfer of the message of the advertisement, and rendering the product more appealing and easier to remember for the con- sumers (Telibaşa, 2015, pp.127-135).

This point is further emphasised by studies asserting that the successfulness of metaphors in advertisements is measured by how efficiently they are encoded and retrieved. Peterson et al. propose that fusion is the most successful form of metaphor in advertisements (two distinguishable images/ objects fused together), followed by juxtaposition (two distinguishable images/objects placed next to each other) - Peterson et al., 2016, pp. 65-74.

Intertextuality in advertising is achievable with metaphors, as well as graphology and general verbal content. Intertextual metaphors are culturally conditioned because, as is the case with intertextuality in general, the recipient of the message must be aware of the context and the pretext. In advertising, it serves the purpose of triggering familiar concepts in the minds of the receivers of the message, and, ultimately, inducing the desire to purchase a product (Zantides, 2016, pp. 65-74). 
Culturally conditioned content in advertising poses a particular difficulty for translators, especially if advertisements cross cultural, as well as linguistic, boundaries. Ho summarises the body of research on translating advertisements with a note that cross-cultural translation is far more than adapta- tion and transfer (Ho, 204, pp. 221-243). As is the case with the translation of metaphors, when conceptual domains from the source language ought to be decomposed, understood, and then recomposed in the target language (Maalej, 2008, pp. 60-82), advertising messages must be converted into language that is adapted to the mindset of the target-language culture (both linguistically and ideologically). Therefore, translation is a process of intercultural communication, and translators ought to provide marketing services and understand the basics of marketing in order to be able to interpret an advertisement as a whole (Valdés-Rodrígues, 2016, pp. 130-153).

An illustration of this argument can be found in the analysis of metaphors in advertisements, provided by Filipović-Kovačević (2013). The author analyses advertisements in English, focusing on the structure, the pragmatic, the conceptual and the textual-visual level of the message, and translates them into Serbian. The given method provides a way of integrating logically incompatible domains, or a mental mechanism for constructing meaning. One such example is an advertisement for Heinz ketchup - a bottle of ketchup standing next to a semi-burned potato chip, with the slogan "Heinz hot ketch-up". Structural analysis encompasses the title and the image. At the pragmatic level of analysis, it can be inferred that the logical incompatibility between concepts stems from the fact that ketchup is not hot in terms of temperature; therefore, it cannot burn food. At the conceptual level, the domains that come into play are those of spiciness and heat. Finally, this leads to the conceptual metaphor in the advertisement that 'intensity is heat'. Thus, "Heinz vruć/vreo kečap" would serve as an adequate translation of the example at hand. An-other slightly more challenging example is that of Spyware Doctor (a spyware computer program). The image of a big, black dog standing next to a small, black-and-white dog is featured (the big dog is the smaller dog's guardian). The bottom left corner of the advertisement contains a box with an image of a doctor and a stethoscope, saying "Spyware Doctor", and the line "When it comes to your protection against spyware, choose the solution that has as much bite as it has bark!" At the pragmatic level of analysis, it is possible to spot the logical incompatibilities between the concepts of: protecting comput- ers and protecting children (the big dog guarding the small one); protecting computers and protecting patients (the doctor has a stethoscope); protecting computers and protecting owners (the dogs both bark at and bite potential attackers). At the conceptual level, the domains that come into play are child protection, patient protection, owner protection and computer protection. The integration process revolves around the analogy between the different kinds of protection, forming a long line until the concept of computer protection is reached. The process of decomposing an underlying metaphor results in a thorough understanding of the interplay between the conceptual domains, which can then be successfully transferred into other languages. It is even pos- sible to identify the metaphors that dominate 
a particular register and explain their characteristics. One such example is the exploration of register metaphors in advertisements for internet security programs, which demonstrates how frequently such programs are anthropomorphised (Ibid., pp. 563571). For example, the dominant domains for anti-virus programs are medicine, war, intelligence, androids and crime ("Kaspersky Anti-Virus 2011 is very effective at blocking new malware attacks" - the domain of war; "Worried about cybercrime? ESET will protect you..." - the domain of crime). Similarly, backup programs are projected as mechanics and ghosts (TuneUp Utilities 2012 - the domain of mechanics; StorageCraft Shadowprotect Desktop 4 - the domain of ghosts) - Ibid. Clearly, an in-depth exploration of metaphors in advertisements from a conceptual standpoint can provide an insight into how the products that are being advertised are perceived from an ideological standpoint. This aspect of analysis is critical in understanding how a particular product falls into the associative network of concepts that it is surrounded by. Consequently, this type of analysis is a prerequisite for the successful transfer of the linguistic and visual content that comprise metaphors in advertisements.

Translation of advertisements has been on the rise, hand in hand with the process of globalisation, business expansion through global and inter-governmental trade deals and international marketing. Cultural barriers (ideologies, beliefs, values etc.) do pose a problem in translation, but global non-translated campaigns may not always prove to be a solution to this problem, as such a strategy may cause certain ideological tensions between cultures (Valdés, 2011, pp. 1-6). The strategy of nontranslation is certainly useful for brands that are competitive on the international market and wish to establish themselves as universal brands. However, even in a period as dynamic as the 21 st century, a lingua franca fails to dominate the global market. Even within Europe, advertisements in English are translated for practical needs or as a result of institutional norms, such as the Toubon Law, in France, which pro- tects the French language from the influx of Anglicisms into it (Ibid.). After all, despite the effects of globalisation, every culture contains a unique set of val- ues and beliefs, archetypes, history, myths and symbols, and cognitive maps, within which any new information must be fed, which is why advertisements are frequently subject to adaptation to other markets (De Mooij, 2004, pp. 179- 198). The second available translation strategy is that of combining non- translation (of the main body of the advertisement) with localisation of the marginal content. The third strategy is localisation. Localisation entails not only linguistic transfer, but also the creation of an entity that the recipients in the target language culture can recognise, thus crossing cultural barriers (Val- dés, 2011, pp. 1-6).

Unlike with metaphor translation, which, according to Mandelblit's Cognitive Translation Hypothesis (Mandelblit, 1995, pp. 482-495), is concerned with successful transference of the cognitive domains of metaphors, translation of advertisements is concerned with successfully meeting the needs of the consumers (Ho, 2004, pp. 221-243). Therefore, the essence of the process of translating advertisements is 
the retention of the persuasive function of adver- tising. Consequently, their persuasiveness must be adapted to the criteria of the target-language culture. Translating only the linguistic content in advertising, whilst ignoring the cultural content, is like painting only the tip of an ice- berg in the hope that the entire iceberg gets painted (De Mooij, 2004, pp. 179- 198).

\section{CONCLUSION}

An in-depth analysis of advertising messages would require a resourceful and meticulous approach to all the critical aspects that comprise the art and science of advertising, and all the areas of human existence that are affected by it. If the mission of the translator in the context of advertising mes- sages is to understand marketing as much as he/she understands translation, then the mission of the researcher in the same context is to be an economist, a psychologist, a sociologist, a linguist and a research analyst. Even a purely lin- guistic analysis must have a strictly defined scope so as to reach valid and verifiable conclusions.

The starting premise of this paper is that language and culture cannot be isolated from each other in the study of the discourse of advertising. That initial premise has dictated the structure of this paper, placing particular emphasis on the areas where language and culture overlap. The exploration of the translation of advertisements is particularly illustrative of this matter, as it demonstrates the complications that translators encounter in transferring the content of an advertisement in its entirety across cultural boundaries. The nuances that the subtext and the paralanguage of the advertisement carry may make perfect sense in one culture, but may cause unwanted errors and mis- understandings in another.

Since advertising messages have a strong persuasive function, pragmatic research of advertising messages certainly has the potential to elaborate the functional aspect of advertising to a great extent. However, it is only by merging disciplines that the full scope of impact of advertising can be comprehended. Such an encyclopaedic endeavour would need to cover almost two centuries of socio-economic development, in the form of a comparative analysis, so as to provide valid conclusions regarding the nature and impact of advertising.

\section{BIBLIOGRAPHY}

Alosque, I. N. (2015), "Visual wine metaphor and metonymy in ads", Procedia - Social and Behavioral Sciences, Vol. 173, No. 1, pp. 125-131.

Alosque, I.N. (2015), "Determining the Rhetorical Nature of Visuals in Advertising", Procedia - Social and Behavioral Sciences, Vol. 173, No. 1, pp. 234240 . 
Alosque, I.N. (2015), "The role of text in the identification of visual metaphor in adver- tising", Procedia - Social and Behavioral Sciences, Vol. 212, No. 1, pp. 309-315.

Beale, K., Malson, H., Tischner, I. (2016), "Deconstructing real women: Young women's readings of advertising images of plus-size models in the UK", Feminism and Psychology, Vol. 26, No. 3, pp. 378-386.

Berger, A.A. (2015), Ads, Fads, and Consumer Culture: Advertising's Impact on American Character and Society, 5th Ed., Maryland: Rowman \& Littlefield, pp. 99-118.

Bernays, E.L. (1928), "Manipulating the public opinion: the why and the how", American Journal of Sociology, Vol. 33, No. 6, pp. 958-971.

Boltz, M.G., Mangigian, G.M., Allen, M.B. (2016), "Phonetic symbolism and memory for advertisements", Applied Cognitive Psychology, Vol. 30, No. 1, pp. 1088-1092.

Brandt, A.M. (2007), The Cigarette Century: The Rise, Fall, and Deadly Persistence of the Product that Defined America, Basic Books, New York.

Colette, S. (2015), "Eroticizing Eve: a narrative analysis of Eve images in fashion magazine advertising", Journal of Feminist Studies in Religion, Vol. 31, No. 2, pp. 5-24.

Cook, G. (2001), The Discourse of Advertising, 2nd ed., Routledge, New York.

De Mooij, M. (2004), "Translating advertising: painting the tip of an iceberg", The Translator, Vol. 10, No. 2, pp. 179-198.

Durand, R.M., Lambert, Z.V. (1985), "Alienation and criticism of advertising", Journal of Advertising, Vol. 14, No. 3, pp. 9-17.

Filipovic-Kovacevic, S. (2013), "Is your computer a victim? Conceptual metaphors in advertisements for internet security programs", Languages and Cultures in Time and Space, Vol. 1, pp. 563-571.

Filipovic-Kovacevic, S. (2013), Implied meanings in advertisements in English and Serbian, Faculty of Philosophy, Novi Sad.

Forceville, C. (1996), Pictorial Metaphor in Advertising, Routledge, London.

Herman, S., Chomsky, N., Said, E. (1988), Manufacturing Consent: The Political Economy of the Mass Media, Pantheon Books, New York.

Ho, G. (2004), "Translating advertisements across heterogeneous cultures", The Translator, Vol. 10, No. 2, pp. 221-243.

Johnston, J., Taylor, J. (2008), "Feminist consumerism and fat activists: a comparative study of grassroots activism and the Dove Real Beauty campaign", Signs, Vol. 33, No. 4, pp. 941-966.

Kissine, M. (2008), "Locutionary, Illocutionary, Perlocutionary", Language and Linguis- tics Compass, Vol. 2, No. 6, pp. 1189-1202.

Köhler, W. (1947), Gestalt Psychology: An Introduction to New Concepts in Modern Psychology. University of Michigan, Liveright.

Lakoff, G., Johnson, M. (1980), Metaphors we live by, University of Chicago Press. 
Lakoff, G., Johnson, M. (1982), "The metaphorical structure of the human conceptual system", Cognitive Science, Vol. 4, No. 1, pp. 195-208.

Lakoff, R.T. (1981), "Persuasive discourse and ordinary conversation, with examples from advertising" in Analyzing Discourse: Text and Talk, D. Tannen, Ed. Washington DC: Georgetown University Press, pp. 25-42.

Lewis, R.D. (2005), When Cultures Collide: Leading Across Cultures, 3rd ed., Nicholas Brealey Publishing, London, pp. 9-15.

Maalej, Z. (2008), "Translating metaphor between unrelated cultures: A cognitivepragmatic perspective”, Sayyab Translation Journal, Vol. 1, No. 1, pp. 60-82.

Mager, J., Helgeson, J.G. (2011), "Fifty years of advertising images: some changing perspectives on role portrayals along with enduring consistencies", Sex Roles, Vol. 64, No. 1, pp. 238-252.

Mandelblit, N. (1995), "The cognitive view of metaphor and its implications for trans- lation" in Translation and Meaning, Part 3, T. Marcel and B. Tomasczyk, Eds. Universitaire Press, Maastricht, pp. 482-495.

Morierty, M., Mitchel, N., Wells, W. (2012), Advertising and IMC, Pearson Education. England.

O'Connell, A. (2014), “Should marketing or R\&D have more power?", Harvard Business Review, July 2014.

Peterson, M., Wise, K., Ren, Y., Wang, Z., Yao, J. (2016), “Memorable metaphor: how different elements of visual rhetoric affect resource allocation and memory for advertisements", Journal of Current Issues and Research in Advertising, Vol. 37, No. 1, pp. 65-74.

Solomon, M., Bamossy, G., Askegaard, S., Hogg, M.K. (2006), Consumer Behaviour: A European Perspective, 3rd Ed., Essays: Pearson Education Limited, pp. 74-78.

Telibaşa, G. (2015), "Image and representation. The language of food advertisements", Interstudia, Vol. 18, No. 1, pp. 127-135.

Valdés, C. (2011), "Advertising translation", in Handbook of Translation Studies, Vol. 2, Y. Gambier, and L. Van Doorslaer, Eds. John Benjamins Publishing Company, Amsterdam, pp. 1-6.

Valdés-Rodrígues, C. (2016), "Globalization and localization in advertising translation: a love hate relationship?" Revista de Lenguas para Fines Especificos, Vol. 22, No. 2, pp. 130-153.

Van Hooft, A., Van Mulken, M., Nedertigt, U. (2013), "Cultural differences? Visual metaphor in advertising: comprehension and tolerance of ambiguity in four European countries", in Advances in Advertising Research, Vol. 4: The Changing Role of Advertising, S. Rosengren, M. Dahlén, and S. Okazaki, Eds. Springer Gabler, pp. 351-364.

Yorkston, E., Menon, G. (2004), “A sound idea: phonetic effects of brand names on consumer judgments", Journal of Consumer Research, Vol. 31, No.1, pp. 4351. 
Zantides, E. (2016), "Visual metaphors in communication: Intertextual semiosis and déjà vu in print advertising", Romanian Journal of Communication and Public Relations, Vol. 18, No. 3, pp. 65-74.

Zotos, Y.C., Tsichla, E. (2014), "Female stereotypes in print advertising: a retrospective analysis", Procedia - Social and Behavioural Sciences, Vol. 148, No. 1, pp. 446-454. 